\title{
EL VIAJERO COMO TRADUCTOR DE CONCEPTOS: ESTUDIO DE LOS HISPANISMOS E INDIGENISMOS EN DER WOCHENMARKT IN CARTAGO (1853)
}

The traveller as a concept's translator: study of the hispanic and indigineous words in Der Wochenmarkt in Cartago (1853)

\author{
LÍA DE LUXÁN HERNÁNDEZ \\ Universidad de Las Palmas de Gran Canaria (España) \\ lia.deluxan@ulpgc.es
}

Resumen

El objetivo de este trabajo es el análisis de los hispanismos e indigenismos que emplea el austríaco Karl Ritter von Scherzer (1821-1903) en la descripción de un mercado local costarricense y se enmarca dentro de las investigaciones de incorporación de términos americanos en las lenguas europeas. El procedimiento utilizado para ello en este paper consiste en un gradiente creado mediante distintas metodologías de análisis filológicas, traductológicas y culturales. Los resultados arrojan indicios acerca de la domesticación (equivalencia dinámica) o extranjerización (importar lo exótico a lectores europeos) de esas voces, así como ponen de relieve que el viajero-científico es más que un mediador intercultural: es un traductor de tradiciones y conceptos.

Palabras clave: Literatura de viajes; Costa Rica; siglo XIX; Karl Ritter von Scherzer; Hispanismos; Indigenismos; Traducción histórica.

\begin{abstract}
The aim of this piece of work is to analyse the Hispanic and Indigenous words that are to be found in a German description of a market in Cartago written by Karl Ritter von Scherzer (18211903). In order to do that an ad hoc gradient (as a result of a compilation of philological, translation and cultural methodologies) will be applied. This analysis will show that there are some words that are either domesticated (a dynamic equivalence will be used) or foreignized (the terms will not be translated), so as the traveller-scientist is more than an intercultural intermediary: he is a translator of traditions and concepts.
\end{abstract}

Key words: Travel literature; Costa Rica; $19^{\text {th }}$ Century; Karl Ritter von Scherzer; Hispanic words; Indigenous words; Historical translation.

\section{PRESENTACIÓN DEL TEMA Y MARCO TEÓRICO GENERAL}

\subsection{PlanteAMiENTO GENERAL}

La literatura de viajes, tal y como apunta Raposo (2014, p. 93), es una fuente importantísima de conocimiento de las relaciones interculturales; estamos ante un género que actúa como centro de documentación de épocas pretéritas y, por tanto, también de 
entendimiento de cómo una lexía o una costumbre ha podido asimilarse en una lenguacultura que, en un principio, le era extraña. Los viajeros-científicos-documentalistas deben verse como una figura impulsora de neologismos y de nuevas tradiciones, y no solamente como mediadores interculturales, sino que, a nuestro juicio, son traductores de tradiciones y conceptos y, extrapolando las ideas de Martinell (1992) y de Ribas (2005), brindan testimonios que remueven la conciencia lingüística.

El interés por la literatura de viajes como fuente de investigación de los estereotipos culturales es ascendente; y en España se demuestra especialmente esa tendencia en el estudio de la prosa generada por alemanes en sus viajes a España, como el libro editado por Raposo Fernández y García Wistädt (2009), que lleva por título Viajes y viajeros entre ficción y realidad. Alemania-España, o, entre otros muchos, el de Friedrich-Stegmann (2014), denominado La imagen de España en los libros de los viajeros alemanes del siglo XVIII. Es importante también destacar dentro de este campo, la labor académica de Sarmiento Pérez $(2005,2007)$ y de Soca Hernández (2010), así como de su grupo de investigación CAN-AL, pues ponen el acento en la particularidad de las islas Canarias de los viajeros alemanes.

Este artículo puede clasificarse dentro del contexto de investigación de la literatura generada por viajeros (que no turistas en el sentido actual del término) alemanes; y se centra en el estudio de los hispanismos e indigenismos que se utilizan en un texto alemán de mediados del siglo XIX, en el que se describe cómo transcurren las jornadas de un mercado local en Costa Rica. Santana Quintana (2017), guiada por una metodología ideada con anterioridad por Cáceres-Lorenzo (2014, p. 120), a la que haremos alusión más adelante, aplica en dos textos alemanes del siglo XVI parte del análisis que aquí nos proponemos (únicamente en lo que se refiere a indigenismos). Batista Rodríguez y Sarmiento Pérez (2007), al contrario que Santana Quintana, sí se han ocupado del análisis de hispanismos (y también de los canarismos, como una especificidad significativa dentro de estos), aunque en sus estudios no se utiliza ningún instrumento de medición y catalogación.

Pretendemos analizar las palabras aunando cuatro estrategias metodológicas: 1) el grado de integración de las palabras en la lengua alemana (vitalidad de los términos); 2) las técnicas de la "domesticación" y "extranjerización", que acogeremos de las teorías de la traducción en general para extrapolarlas a nuestro estudio; 3) las estrategias de traducción histórica (De Luxán Hernández, 2012, pp. 219-224), que también adaptaremos; y 4) las técnicas de Beller (2006, pp. 105-124) de descripción de las relaciones interculturales, a las que les daremos una interpretación adecuada a nuestro objeto de estudio. No obstante, la segunda mencionada (la domesticación vs. la extranjerización) actuará como denominador común de todas ellas.

Como puede desprenderse de todo lo anterior, el artículo que aquí nos concierne aúna las filologías alemana y española, así como los estudios culturales y el campo de la traducción y la interpretación; estamos ante una investigación multidisciplinar que pone 
de relieve la figura del viajero como traductor de conceptos, motivo por el que se diseña un método que aúna las disciplinas antes mencionadas y permite analizar las decisiones de aquel en la redacción de su texto.

\subsection{SOBRE EL LIBRO Y LOS VIAJEROS EN GENERAL}

El libro en el que se enmarca el texto en el que se centra nuestro análisis se titula Die Republik Costa Rica in Central Amerika mit besonderer Berücksichtigung der Naturverhältnisse und der Frage der deutschen Auswanderung und Colonisation. Reisestudien und Skizzen aus den Jahren 1853 und 1854 ("La república de Costa Rica en Centroamérica, haciendo especial énfasis en el comportamiento de la naturaleza, así como en la emigración alemana y la colonización. Estudios de viaje y esquemas correspondientes a los años 1853 y 1854”), y fue publicado en Leipzig en 1856. Se trata de un libro escrito en letra gótica a cuatro manos por el austríaco experto en ciencias naturales Karl Ritter von Scherzer (1821-1903) y el viajero-naturalista-geógrafo (entre otras cosas) Moritz Wagner (1813-1887), aunque en él se diferencia la autoría de los diferentes capítulos, porque al final de cada uno de ellos, el autor plasma sus iniciales. El ejemplar con el que hemos trabajado para esta investigación es de la Harvard College Library, cedido por Cameron Forbes el 26 de junio de 1906. Nos centraremos en este artículo en el capítulo decimoquinto (pp. 238-244) denominado Der Wochenmarkt in Cartago ("El mercado en Cartago"), escrito por el primero de ellos.

Nuestro libro objeto de análisis no versa sobre España, sino de Centroamérica y, en concreto, Costa Rica. Hay también muchos estudios de diferentes disciplinas (botánica, geografía, historia, filología, entre otras) que se han interesado por tomar como fuente principal de sus investigaciones la literatura generada por viajeros científicos alemanes a Hispanoamérica. México es y ha sido uno de los países que más interés ha despertado en esta temática, entre los que podemos resaltar, desde nuestra óptica del alemán como lengua vehicular, el artículo de Mendoza Vargas (2016), que lleva por título La mirada alemana sobre México en tres viajeros: Alexander von Humboldt (17691859), Friedrich Ratzel (1844-1904) y Adolph Reichwein (1898-1944).

Los viajeros-científicos de lengua alemana del siglo XIX que más han destacado por sus estudios de Centroamérica son los dos autores del libro que nos convoca, Mortiz Wagner (1813-1887) y Karl Ritter von Scherzer (1821-1903), así como Wilhem Heine (1827-1885), del que podemos citar el libro Wanderbilder aus Central Amerika. Skizzen eines deutschen Malers (1853) y Wilhem Maar (1819-1904), que publicó en 1863 el libro Reise nach Central Amerika. 


\subsection{PRESUPUESTOS INICIALES}

¿Qué entendemos por "hispanismo" en este artículo? Muchas veces, cuando se emplea este término, se hace alusión a "la presencia del español en obras americanas como el estudio de la lengua, la literatura y la cultura española" (Zuleta, 1992, p. 950), pero aquí lo que nos concierne es el vocabulario, por lo que adoptaremos la definición número 2 del Diccionario de la Real Academia Española (en adelante, DRAE): "vocablo o giro de la lengua española empleado en otra".

¿Y por "indigenismo"? Podríamos establecer las mismas acepciones que en el caso anterior, pero centrándonos en los pueblos y lenguas indígenas, es decir, primigenios, de América. Al igual que con "hispanismo", vamos a adoptar la definición correspondiente al vocabulario del DRAE (la número 4): "vocablo, giro, rasgo fonético, gramatical o semántico que pertenece a alguna lengua indígena de América o proviene de ella".

Scherzer intercala el uso de hispanismos e indigenismos, que aparecen en su texto, en mayor o menor medida domesticados o extranjerizados; y estos últimos no son siempre originarios del lugar que se describe. Precisamente, Martinell (1992:108, citado en Ribas, 2005, p. 150) establece que para denominar conceptos inexistentes en la lengua meta, hay tres métodos: 1) empleo de palabras de la propia lengua, 2) la creación de nuevos términos y 3 ) de indigenismos.

Es evidente el contacto entre lenguas en Hispanoamérica: la colonización trajo consigo una mezcla de españoles con indígenas (Wagner, 1920, p. 295); lo que explica la doble vía de influencia entre el español y las lenguas amerindias, tal y como señala Cáceres-Lorenzo (2019) para la región de Centroamérica. Zimmerman (1995, pp. 9-34) dedica un artículo a esta temática y cita, entre otros, a Lenz (1893), quien estudió la influencia del araucano en el español de Chile, y a Germán de Granda (1988), que se ha ocupado de analizar el fenómeno de la influencia del guaraní en el español de Paraguay. También hay que tener en consideración el papel de las lenguas indígenas dominantes a la hora de diferenciar el español según las zonas dialectales (Ureña, 1921) y para explicar por qué hay algunas voces propias de una zona determinada que se prefieren a las propias de la lengua indígena del lugar que se describe.

Los principales interrogantes a los que se pretende dar respuesta mediante este artículo son los siguientes: 1) ¿Por qué utiliza un viajero alemán hispanismos o indigenismos? 2) ¿Qué nivel de asimilación tienen esos vocablos? 3) ¿En qué medida actúa el viajero alemán como un traductor?

\section{HACIA UN INSTRUMENTO DE ANÁLISIS INTEGRADOR}

\subsection{PLANTEAMIENTO GENERAL}

A la hora de describir unas costumbres, unos accidentes geográficos, unos víveres, unos árboles..., el viajero toma decisiones de corte traductológico, aun sin ser consciente 136 | Alpha No 52 (Julio 2021) PÁGs. 133-147. ISSN 07 16-4254 
de ello. Es nuestro cometido en este trabajo analizar esas elecciones; y, para ello, adaptaremos ciertas metodologías que nos permitirán observar de una manera más globalizada y pormenorizada al mismo tiempo las diferentes estrategias adoptadas por Scherzer. Comenzaremos explicando el gradiente creado por Cáceres-Lorenzo, que simplificaremos y reinventaremos en aras de su utilidad en nuestro cometido.

Tras la explicación de nuestra nueva clasificación por grados de integración de los hispanismos o indigenismos, describiremos los términos "domesticación" $\mathrm{y}$ "extranjerización", así como introduciremos su aplicación adaptada a las estrategias de transmisión de nuevos conceptos por parte del viajero, y una nueva categoría intermedia; nos centraremos, luego, en las estrategias de traducción histórica, que versionaremos para que se ajusten a nuestro objetivo; después relacionaremos la tipología de Beller de descripción de relaciones interculturales con nuestro estudio; más tarde aunaremos todas ellas, exceptuando el nuevo gradiente, creando tres categorías de "domesticación" y "extranjerización" más aglutinadoras y específicas para nuestro trabajo; y, por último, presentaremos el instrumento de análisis integrador, del que nos valdremos en el siguiente apartado de este artículo para clasificar las decisiones traductológicas de Scherzer de manera más clara.

\subsection{MÉTODO CÁCERES-LORENZO Y SU REINVENCIÓN}

Cáceres-Lorenzo (2014, p. 120), basándose en su propia investigación y en bibliografía acerca de la integración de la terminología indígena (véase Alvar, 1990; Zamora Munné, 1976; Vaquero de Ramírez, 1991; Buesa y Enquita Utrilla, 1992) establece un método de clasificación de los indigenismos de 0 a 5 para analizar aquellos que aparecen en dos textos de corte administrativo de Colombia y Ecuador. El "0" indica la falta de integración (no se adopta ningún indigenismo) y el " 5 " es el polo opuesto y señala que el grado de asimilación es total:

0: No indigenous loanword appears; 1: The indigenous loanword is used but always with an explanation; 2: The indigenous loanword is always associated with a Spanish term that is considered to be a synonym; 3: The indigenous term or its Spanish synonym is used imprecisely; 4: The indigenous loanword is used without an explanation or connotation in any geographical area and with the indigenous loanword's initial meaning; 5; The indigenous loanword appears without explanation in any geographical area, but the linguistic borrowing has expanded its original meaning by including new referents (Cáceres Lorenzo, 2014, p. 120).

Este instrumento de investigación, que nace en un principio con vocación de ser aplicado en el estudio de textos redactados en el español de América, puede ser perfectamente extrapolable al análisis de literatura en diferentes lenguas. Una muestra de ello es el trabajo de Santana Quintana (2017) de los indigenismos al que ya hemos 
aludido. Nosotros proponemos una clasificación en tres grados para analizar la integración hoy respecto de los hispanismos o indigenismos; consideramos que el hecho de que sea más simplista, permite que cataloguemos los hispanismos e indigenismos de una forma más esclarecedora para nuestro propósito.

Figura $\mathrm{N}^{\mathrm{o}}$ 1: Grados de integración de los hispanismos e indigenismos

\begin{tabular}{|c|c|c|c|}
\hline GRADO DE & GRADO N $^{\mathbf{0}}$ & GRADO N $^{\mathbf{2}}$ & GRADO N $^{\mathbf{3}} \mathbf{}$ \\
\cline { 2 - 4 } $\begin{array}{c}\text { INTEGRACIÓN/ } \\
\text { VITALIDAD }\end{array}$ & $\begin{array}{c}\text { No pervivencia en el } \\
\text { idioma alemán }\end{array}$ & Vitalidad parcial & $\begin{array}{c}\text { Vitalidad del término } \\
\text { Pequeña o ninguna } \\
\text { adaptación }\end{array}$ \\
\hline
\end{tabular}

Fuente: Elaboración propia

\subsection{DOMESTICACIÓN VS. EXTRANJERIZACIÓN DE TÉRMINOS}

Desde el momento en el que se pronuncian los términos "domesticación" y "extranjerización", en la mente de todo estudioso de la traducción aparecen los nombres "Nida" y "Venuti"; el primero es el máximo exponente de la equivalencia dinámica y opta por borrar fronteras, por una traducción lo más fluida posible; mientras que el segundo aboga por una traducción de lo extraño, de la transmisión de lo nuevo, de la no elusión de las diferencias culturales. En nuestro caso particular, advertiremos si un hispanismo o indigenismo está domesticado cuando el vehículo para la transmisión del concepto haya sido solamente el alemán; estará extranjerizado si se ha usado precisamente ese hispanismo o indigenismo tal cual (apoyándose en alguna ocasión en la lengua latina); y se catalogará como "domextranjerizado" en aquellos supuestos en los que se domestique y extranjerice a partes iguales; lo que sucederá en los casos en los que, por ejemplo, se ofrezca una explicación del concepto que se quiere transmitir en alemán, y, entre paréntesis, se encuentre el hispanismo o indigenismo; o también, por ejemplo, cuando el autor utilice para una parte del concepto el americanismo y, para otra, el alemán, creando así un nuevo término.

\subsection{ESTRATEGIAS DE TRADUCCIÓN HISTÓRICA ADAPTADAS}

En la traducción de textos históricos (De Luxán Hernández, 2012, pp. 219224), así como en la traducción de conceptos, el productor de nuevos textos (traductor histórico en el primer supuesto y viajero-científico en el segundo) puede adoptar cuatro estrategias: arcaico-documental, documental, docuinstrumental o instrumental; su decisión vendrá motivada por el fin de su texto. En el supuesto de que pretenda que este funcione como un documento de aprendizaje, en el que la utilización de términos o fórmulas extranjerizantes es necesaria, porque la facilidad de la transmisión del mensaje no es el móvil, se decantará por una estrategia documental o arcaico-documental. Si su principal motivo es antagónico a este último, 138 | AlPHa No 52 (JuLIO 2021) PÁGS. 133-147. ISSN 07 16-4254 
lo que significa que lo que persiga sea la ausencia de incomodidad por parte del lector, acudirá a la técnica instrumental. Y, por último, cuando quiera conciliar ambas finalidades, estará ante una aproximación docu-instrumental del texto.

La técnica documental es el tipo de estrategia idónea que se emplea para un público con perfil académico, al que lo extranjerizante le suponga una motivación añadida al tema en sí, pues adquirirá una visión más exacta y global de los conceptos que se pretendan transmitir; en nuestro supuesto, mediante el uso de hispanismos e indigenismos. La finalidad es que sea el lector el que se acerque al qué descrito en el texto, que tenga aquel que hacer un esfuerzo por entender esa cultura o esos conceptos. La arcaico-documental lleva consigo una motivación un poco más perversa en términos académicos: se sobreextranjeriza en aras de recuperar términos o lenguajes más remotos (por ejemplo, con el uso del latín). En este supuesto también se persigue un acercamiento por parte del lector a esas nuevas concepciones que se transmiten, pero con la dificultad añadida de que se le obstaculiza el aprendizaje al acudir a términos anteriores que puede que no domine.

La estrategia instrumental está presidida por procurar el bienestar del lector, en el sentido de que lo que se prioriza no es el acercamiento de este hacia la nueva cultura o nuevos conceptos en forma de documento, como es el caso de las estrategias ya descritas, sino que el proceso que se persigue es el contrario: que sea el texto el que le facilite esa comprensión, que se acerque a él. En nuestro supuesto, el país debe acercarse al lector y no este a aquel. Para ello, Scherzer describe en alemán los nuevos conceptos en vez de hacer uso de hispanismos o indigenismos: se domestican.

La técnica de traducción docuinstrumental es una postura ecléctica: surge tras una negociación (Pym, 1993) entre las dos partes implicadas: el lector y la temática del texto, que, en nuestro estudio es un mercado local costarricense y, por esta razón, lengua-cultura extraña al público alemano-parlante. Este método se adscribe a lo que hemos bautizado como "domextranjerización" y es de aplicación en el texto que nos concierne cuando, por ejemplo, Scherzer combina hispanismos o indigenismos con el alemán, o utiliza el alemán como explicación, pero presenta el americanismo entre paréntesis.

\subsection{TIPOLOGÍA DE BELLER AJUSTADA}

Beller (2006, p. 119 y ss.; citado por Raposo, 2014, p. 94) establece que la descripción de los viajeros se adscribe a una de las siguientes categorías: 1) tipología analógica, 2) tipología antitética, 3) tipología recíproca. Estaremos ante una descripción analógica en el supuesto de que el relato esté escrito en una única dirección, es decir, si se tiene en cuenta solamente el sitio que se visita, esto es, lo extraño y, por tanto, en nuestro estudio, ante la utilización de hispanismos e indigenismos (acompañados en alguna ocasión con una pequeña explicación en latín). 


\section{Lía de Luxán Hernández}

Será antitética, precisamente, cuando se recurra a la antítesis, teniendo como foco principal la lengua-cultura compartida por el autor y el lector, y no la nueva: se domestican los conceptos de forma que la lectura sea menos costosa. Mientras que estaremos ante una técnica de descripción que Beller ha venido a calificar como "recíproca" cuando se intente establecer una comparación productiva, y no tan egoísta o centrista, entre ambas lengua-culturas.

\subsection{DOMESTICAR Y EXTRANJERIZAR DE MANERA GLOBAL}

Figura $\mathrm{N}^{\mathrm{o}} 2$ : Domesticación, domextranjerización y extranjerización

\begin{tabular}{|c|c|c|c|}
\hline $\begin{array}{l}\text { Domesticación vs. } \\
\text { Extranjerización }\end{array}$ & A) Domesticación & B) Domextranjerización & C) Extranjerización \\
\hline $\begin{array}{l}\text { Estrategia } \\
\text { traductora histórica }\end{array}$ & $\begin{array}{l}\text { Traducción } \\
\text { instrumental } \\
\text { Acercamiento de la } \\
\text { lengua-cultura y } \\
\text { temática } \\
\text { especializada al } \\
\text { lector: } \\
\text { domesticación de } \\
\text { conceptos }\end{array}$ & $\begin{array}{l}\text { Traducción docu- } \\
\text { instrumental } \\
\text { Eclecticismo de posturas: } \\
\text { punto común entre ambas } \\
\text { lengua-culturas }\end{array}$ & $\begin{array}{l}\text { Traducción documental } \\
\text { Traducción arcaico- } \\
\text { documental } \\
\text { Acercamiento del } \\
\text { lector a lengua cultura } \\
\text { y la temática } \\
\text { especializada: } \\
\text { extranjerización de } \\
\text { conceptos }\end{array}$ \\
\hline $\begin{array}{l}\text { Tipología } \\
\text { descriptiva }\end{array}$ & $\begin{array}{l}\text { Descripción } \\
\text { antitética: se } \\
\text { destaca lo extraño } \\
\text { con respecto a la } \\
\text { lengua-cultura } \\
\text { compartida por } \\
\text { viajero y lector }\end{array}$ & $\begin{array}{l}\text { Descripción recíproca: se } \\
\text { intenta establecer una } \\
\text { comparación productiva } \\
\text { entre ambas lengua- } \\
\text { culturas }\end{array}$ & $\begin{array}{l}\text { Descripción analógica: } \\
\text { se describe de manera } \\
\text { prácticamente lineal lo } \\
\text { extraño al lector }\end{array}$ \\
\hline $\begin{array}{l}\text { Características } \\
\text { compartidas }\end{array}$ & $\begin{array}{l}\text { Uso únicamente } \\
\text { del alemán para } \\
\text { describir un } \\
\text { concepto }\end{array}$ & $\begin{array}{l}\text { Se utiliza un hispanismo o } \\
\text { un indigenismo } \\
\text { Puede tratase de la creación } \\
\text { de un neologismo } \\
\text { Puede haber una } \\
\text { adaptación parcial al } \\
\text { alemán } \\
\text { El autor puede valerse de } \\
\text { una explicación en alemán } \\
\text { El término } \\
\text { hispano/indígena puede } \\
\text { aparecer entre paréntesis }\end{array}$ & $\begin{array}{l}\text { Se utiliza un } \\
\text { hispanismo o un } \\
\text { indigenismo para la } \\
\text { transmisión de } \\
\text { conceptos } \\
\text { Puede haber una } \\
\text { explicación en latín }\end{array}$ \\
\hline
\end{tabular}

Fuente: Elaboración propia

140 | AlPHA № 52 (JuLIo 2021) PÁGS. 133-147. ISSN 07 16-4254 
Como puede advertirse, en la tabla de arriba se han agrupado tres estrategias bajo el termómetro del análisis primordial en este estudio: la domesticación y la extranjerización, a la que se les une una categoría intermedia ya explicada: la domextranjerización. Esta interrelación de métodos se ha intentado hacer palpable a medida que se han ido introduciendo cada uno de ellos por separado. La domesticación, la traducción instrumental y la descripción antitética son la categoría "A" y vienen definidas por la ausencia de hispanismos e indigenismos strictu sensu, el uso del idioma alemán como vehículo para la transmisión de conceptos extraños y la comparación antitética egoísta, centrada únicamente en el lector y su lengua-cultura.

La categoría "B", presidida por la "domextranjerización", une a esta con la estrategia docuinstrumental (la teoría de la negociación a ojos de Pym -1993-) y la descripción recíproca; se caracteriza por la diplomacia de la traducción viajera, es decir, el productor de la literatura de viajes persigue un acercamiento entre la lengua-cultura que describe y aquella a la que su audiencia y él pertenecen. ¿Cómo consigue este objetivo? Mediante la creación de neologismos, en los que combina hispanismos o indigenismos con palabras alemanas; la utilización del alemán como motor de transmisión, acompañada por el americanismo; una adaptación parcial al alemán; o cualquier otro método conciliador.

Por último, la categoría “C”, orquestada por la "extranjerización”, aúna esta con las estrategias de traducción histórica documental y arcaico-documental, así como con la descripción analógica. El viajero-traductor se da cita en estas decisiones con una audiencia que tiene que hacer un esfuerzo mayor que en los dos supuestos anteriores, porque extranjeriza los conceptos; hace uso de hispanismos e indigenismos en grado puro y, a veces, intenta ayudarlo con una técnica arcaico-documental: la explicación en latín.

\subsection{UNA VISIÓN UNIFICADORA: ANÁLISIS INTEGRADOR}

Figura $\mathrm{N}^{\mathrm{o}}$ 3: Instrumento de análisis integrador de hispanismos/indigenismos en la lengua alemana

\begin{tabular}{|c|c|c|c|c|c|}
\hline $\begin{array}{c}\text { Término en el } \\
\text { texto }\end{array}$ & Página & $\begin{array}{c}\text { Hispanismo/ } \\
\text { Indigenismo }\end{array}$ & $\begin{array}{c}\text { Actualidad } \\
\text { del término }\end{array}$ & A, b o c & Grado \\
\hline
\end{tabular}

Fuente: Elaboración propia

Para poder analizar de manera más clara las decisiones tomadas por Scherzer a la hora de transmitir conceptos, se ha sintetizado en la figura $\mathrm{N}^{\circ} 3$ las dos anteriores; de este modo, tras escribir cómo se transmite el concepto en el texto y en qué página, pasaremos a describirlo como un hispanismo o indigenismo (indicando la lengua amerindia en los supuestos en que el dato sea conocido). Es importante señalar que hay ocasiones en los que la expresión alemana hace alusión a un hispanismo o indigenismo, pero no se nombra. Luego señalaremos qué palabra se usa en alemán hoy para referirse a él; puede 
haber casos en los que no haya alusión a ese concepto, lo que estará representado con dos signos de interrogación. A continuación, adscribiremos la decisión de Scherzer a una de las categorías descritas en la figura $\mathrm{N}^{0}$ 2; en el supuesto de la categoría "C", especificaremos si la estrategia adoptada es documental o arcaico-documental. Por último, le atribuiremos un grado, de acuerdo con lo señalado en el apartado 2.2.

\section{ANÁLISIS DE LOS HISPANISMOS E INDIGENISMOS EN EL TEXTO}

A continuación, haciendo uso de la tabla anteriormente descrita, procedemos al análisis de las decisiones de Scherzer respecto de los hispanismos e indigenismos del capítulo Der Wochenmarkt in Cartago ("El mercado en Cartago") del libro Die Republik Costa Rica in CentralAmerika mit besonderer Berücksichtigung der Naturverhältnisse und der Frage der deutschen Auswanderung und Colonisation. Reisestudien und Skizzen aus den Jahren 1853 und 1854 ("La república de Costa Rica en Centroamérica, haciendo especial énfasis en el comportamiento de la naturaleza, así como en la emigración alemana y la colonización. Estudios de viaje y esquemas correspondientes a los años 1853 y 1854"):

Figura № 4: Análisis de los hispanismos e indigenismos en Der Wochenmarkt in Cartago

\begin{tabular}{|c|c|c|c|c|c|}
\hline $\begin{array}{l}\text { TÉRMINO } \\
\text { EN EL } \\
\text { TEXTO } \\
\end{array}$ & PÁGINA & $\begin{array}{l}\text { HISPANISMO/ } \\
\text { INDIGENISMO }\end{array}$ & $\begin{array}{c}\text { ACTUALIDAD } \\
\text { DEL } \\
\text { TÉRMINO }\end{array}$ & $\mathrm{A}, \mathrm{B}$ OC & GRADO \\
\hline Сатро & 238 & HISPANISMO & Land & $\begin{array}{c}\text { C } \\
\text { documental }\end{array}$ & 1 \\
\hline $\begin{array}{c}\text { Banane oder } \\
\text { Paradiesfeige } \\
\text { (Musa } \\
\text { paradisiaca } \\
\text { und Musa } \\
\text { sapientum }\end{array}$ & 239 & HISPANISMO & Banane & $\mathrm{B}$ & 3 \\
\hline Maisbrotes & 239 & $\begin{array}{c}\text { INDIGENISMO } \\
\text {-Mais- } \\
\text { Tamales }\end{array}$ & $\begin{array}{c}\text { Mais } \\
\text { Maisprossen }\end{array}$ & B & 2 \\
\hline $\begin{array}{c}\text { Platanos (wie } \\
\text { die Spanier die } \\
\text { Paradiesfeigen } \\
\text { nennen) }\end{array}$ & 239 & HISPANISMO & $\begin{array}{c}\text { Banane } \\
\text { (Voz del Congo) }\end{array}$ & B & 1 \\
\hline $\begin{array}{l}\text { Anone (Anona } \\
\text { Humboldtii) }\end{array}$ & 239 & $\begin{array}{c}\text { INDIGENISMO } \\
\text { Guaraní }\end{array}$ & Ananas & $\begin{array}{c}\mathrm{C} \\
\text { documental }\end{array}$ & 3 \\
\hline Guanabanas & 239 & $\begin{array}{c}\text { INDIGENISMO } \\
\text { Taíno }\end{array}$ & $\begin{array}{l}\text { Guanabana- } \\
\text { Frucht }\end{array}$ & $\begin{array}{c}\text { C } \\
\text { documental }\end{array}$ & 2 \\
\hline Granadilla & 239 & HISPANISMO & Passionsfrucht & $\begin{array}{c}\mathrm{C} \\
\text { documental }\end{array}$ & 1 \\
\hline Membrillas & 239 & HISPANISMO & Quitte & $\mathrm{C}$ & 1 \\
\hline
\end{tabular}

142 | AlPHA № 52 (Julıo 2021) PÁGS. 133-147. ISSN 07 16-4254 
El viajero como traductor de conceptos: estudio de los hispanismos e indigenismos

\begin{tabular}{|c|c|c|c|c|c|}
\hline $\begin{array}{l}\text { [tendría que ser } \\
\text { "membrillos"] }\end{array}$ & & & & documental & \\
\hline Cayotes & 239 & $\begin{array}{c}\text { INDIGENISMO } \\
\text { Nahua }\end{array}$ & Chayote & $\begin{array}{c}\text { C } \\
\text { documental }\end{array}$ & 3 \\
\hline $\begin{array}{c}\text { Die Früchte } \\
\text { der } \\
\text { Mauritiuspalme }\end{array}$ & 239 & HISPANISMO & $\begin{array}{l}\text { Die Früchte der } \\
\text { Mauritiuspalme }\end{array}$ & $\mathrm{A}$ & 1 \\
\hline Zapotes & 239 & $\begin{array}{c}\text { INDIGENISMO } \\
\text { Nahua }\end{array}$ & Sapotillbaum & $\begin{array}{c}\mathrm{C} \\
\text { documental }\end{array}$ & 1 \\
\hline Aguacates & 239 & $\begin{array}{c}\text { INDIGENISMO } \\
\text { Nahua }\end{array}$ & $\begin{array}{c}\text { Avocado } \\
\text { (Voz del Caribe) }\end{array}$ & $\begin{array}{c}\text { C } \\
\text { documental }\end{array}$ & 1 \\
\hline Tacacos & 239 & $\begin{array}{l}\text { INDIGENISMO } \\
\text { Huetar }\end{array}$ & ¿? & $\begin{array}{c}\mathrm{C} \\
\text { documental }\end{array}$ & 1 \\
\hline $\begin{array}{l}\text { Chirimollas } \\
\text { (es con "y") }\end{array}$ & 239 & INDIGENISMO & Cherimoya & $\begin{array}{c}\text { C } \\
\text { documental }\end{array}$ & 3 \\
\hline $\begin{array}{l}\text { Chilamotes } \\
\text { (el singular } \\
\text { debería ser } \\
\text { "chilamate") }\end{array}$ & 239 & $\begin{array}{l}\text { INDIGENISMO } \\
\text { Nahua }\end{array}$ & ¿? & $\begin{array}{c}\mathrm{C} \\
\text { documental }\end{array}$ & 1 \\
\hline $\begin{array}{c}\text { Yuca (Jatropha } \\
\text { manihoca L.) }\end{array}$ & 240 & $\begin{array}{c}\text { INDIGENISMO } \\
\text { Tahíno }\end{array}$ & Yucca & $\begin{array}{c}\mathrm{C} \\
\text { arcaico- } \\
\text { documental }\end{array}$ & 3 \\
\hline $\begin{array}{c}\text { Camotes oder } \\
\text { süße Kartoffel } \\
\text { (Convulvus } \\
\text { Batata L.) }\end{array}$ & 240 & $\begin{array}{c}\text { INDIGENISMO } \\
\text { Nahua }\end{array}$ & Süße Kartoffel & $\mathrm{B}$ & 1 \\
\hline $\begin{array}{c}\text { Tomatos } \\
\text { (Solanum } \\
\text { Licpersicum) }\end{array}$ & 240 & $\begin{array}{l}\text { HISPANISMO } \\
\text { VÍA } \\
\text { INDIGENISMO }\end{array}$ & Tomate & $\begin{array}{c}\mathrm{C} \\
\text { arcaico- } \\
\text { documental }\end{array}$ & 3 \\
\hline $\begin{array}{c}\text { Die } \\
\text { gewöhnliche } \\
\text { Kartoffel } \\
\text { (Solanum } \\
\text { Tuberosum) }\end{array}$ & 240 & $\begin{array}{c}\text { INDIGENISMO } \\
\text { Quechua }\end{array}$ & Kartoffel & $\mathrm{A}$ & 1 \\
\hline $\begin{array}{c}\text { Die } \\
\text { peruanische } \\
\text { Kartoffel (papa } \\
\text { forastera) }\end{array}$ & 240 & $\begin{array}{c}\text { INDIGENISMO } \\
\text { Quechua }\end{array}$ & Kartoffel & B & 1 \\
\hline $\begin{array}{c}\text { Eine kleine } \\
\text { runde Art } \\
\text { (papa crioya) }\end{array}$ & 240 & $\begin{array}{c}\text { INDIGENISMO } \\
\text { Quechua }\end{array}$ & Kartoffel & B & 1 \\
\hline $\begin{array}{l}\text { Die eingefuihrte } \\
\text { Kartoffel, und }\end{array}$ & 240 & $\begin{array}{c}\text { INDIGENISMO } \\
\text { Quechua }\end{array}$ & Kartoffel & $\mathrm{A}$ & 1 \\
\hline
\end{tabular}




\begin{tabular}{|c|c|c|c|c|c|}
\hline $\begin{array}{l}\text { zwar die } \\
\text { Cajuela }\end{array}$ & & & & & \\
\hline $\begin{array}{l}\text { Gelber Mais } \\
\text { (Zea Mais L.) }\end{array}$ & 241 & $\begin{array}{c}\text { INDIGENISMO } \\
\text { Tamales }\end{array}$ & Gelber Mais & B & 2 \\
\hline $\begin{array}{c}\text { Cacao } \\
\text { (Theobroma } \\
\text { Cacao L.) }\end{array}$ & 241 & $\begin{array}{c}\text { INDIGENISMO } \\
\text { Nahua }\end{array}$ & Kakao & $\begin{array}{c}\mathrm{C} \\
\text { arcaico- } \\
\text { documental }\end{array}$ & 3 \\
\hline Cigarren & 241 & $\begin{array}{c}\text { INDIGENISMO } \\
\text { Maya }\end{array}$ & Zigarre & $\begin{array}{c}\text { C } \\
\text { documental }\end{array}$ & 3 \\
\hline Unzen & 243 & HISPANISMO & Unze & $\mathrm{A}$ & 3 \\
\hline Pesos & 243 & HISPANISMO & Peso & $\begin{array}{c}\mathrm{C} \\
\text { documental }\end{array}$ & 3 \\
\hline
\end{tabular}

Fuente: elaboración propia

Como puede comprobarse, son veintisiete decisiones viajero-traductológicas las que aquí nos conciernen; de ellas, catorce aparecen en la misma página: la 239; dieciocho son indigenismos (el nahua predomina sobre las demás lenguas amerindias) y nueve son hispanismos; dieciséis pertenecen a la categoría " $\mathrm{C}$ " (de las que solamente tres son adscritas a la estrategia arcaico-documental), siete con calificables como " $\mathrm{B}$ ", y cuatro se catalogan bajo "A"; catorce no se han integrado en el lenguaje alemán (grado $\mathrm{n}^{\mathrm{o}} 1$ ), diez sí lo han hecho (grado $n^{\circ} 3$ ) y tres, de manera parcial (grado $n^{\circ} 2$ ). Se destaca que hay un indigenismo al que se hace alusión en cuatro ocasiones de distintas maneras ("papa") y otro que se menciona en dos ("mais").

\section{CONCLUSIONES}

El viajero productor de textos es un traductor de conceptos, tal y como se refleja en el título de este artículo y se ha podido constatar a lo largo de estas páginas: es un tomador de decisiones que involucran la domesticación, domextranjerización o extranjerización de las palabras, estrategias generales que pueden aunarse con las técnicas de traducción de textos históricos y la tipología descriptiva diseñada por Beller. Se decantará por alguna de estas tres categorías, que hemos conceptualizado en " $\mathrm{A}$ ", "B" o "C", respectivamente, según el fin último que persiga. Así, en nuestro documento en particular, hará uso de hispanismos e indigenismos en el momento que tenga por fin una estrategia documental o arcaico-documental (mediante el empleo del latín) y, por tanto, tenga que extranjerizar conceptos en aras de que el público se nutra de una manera más profunda de la lengua-cultura que él está descubriendo, por lo que se acudirá a una descripción analógica o lineal del mercado, en nuestro caso particular.

Los hispanismos e indigenismos en el texto alemán pueden conformar un nuevo término (neologismo) o ser presentados entre paréntesis, después de que se haya introducido el término en alemán. En tal caso, el viajero-traductor de conceptos optará por la técnica de la negociación de Pym (1993) o la domextranjerización, en la que tiene 144 | AlPHa No 52 (Julio 2021) PÁGs. 133-147. ISSN 07 16-4254 
protagonismo la traducción docuinstrumental: se procura un acercamiento entre la lengua-cultura y el público. La técnica de descripción utilizada será la recíproca.

También se puede hacer alusión a un hispanismo o indigenismo sin necesidad de mencionarlo: ello sucede cuando se domestican los conceptos y se acude a la lenguacultura compartida entre escritor y lector, en aras de facilitarle la comprensión de lo que quiere transmitir. Es el caso del empleo de una técnica instrumental: el texto no actúa en esos casos como documento, sino como instrumento, como vehículo de transmisión de conocimientos, en una forma menos académica que la perseguida por las estrategias documental y docuinstrumental, en las que la extranjerización y, por esta razón, el uso de hispanismos e indigenismos, es indispensable.

Hemos comprobado que en el texto de siete páginas que aquí nos concierne hay veintisiete tomas de decisiones que coinciden con voces utilizadas en esta región de América (Cáceres-Lorenzo, 2019), en las que se ven involucradas la utilización de hispanismos e indigenismos (no siempre de manera directa); de esas veintisiete, $51 \%$ de todas ellas aparecen en una sola página (239); y 67\% representa la frecuencia de indigenismos respecto de hispanismos, lo que explica por qué la categoría "C" (extranjerización, traducción documental o arcaico-documental y descripción analógica) tenga una aplicación de 59\%.

Concluiremos estas reflexiones finales resumiendo los datos de integración de esos hispanismos e indigenismos en la lengua alemana; así habría que señalar que 51\% es el porcentaje correspondiente a las no integraciones de estos; 37\%, a los que se han incorporado con éxito al alemán y, el restante, a los que han tenido un éxito parcial. La labor del viajero como impulsor de nuevos términos en alemán no es, pues, nada desdeñable: en un texto de siete páginas, $49 \%$ de sus elecciones han sido tenidas en consideración hasta hoy.

\section{OBRAS CITADAS}

Alvar López, Manuel (1990). Americanismos en la "Historia" de Bernal Díaz del Castillo. Madrid: Ediciones de cultura hispánica.

Batista Rodríguez, José Juan y Sarmiento Pérez, Marcos (2007). "Hispanismos (y canarismos) en textos decimonónicos alemanes sobre Canarias". Revista de Filología, 79-88.

Beller, Manfred (2006). "Typologia reciproca. Über die Erhellung des deutschen Nationalcharakters durch Reisen", en: Eingebildete Nationalcharaktere. Vorträge und Aufsätze zur literarischen Imagologie. Göttingen: V + R Unipress,105-124.

Buesa, Oliver y Enguita Utrilla, J.M. (1992). Léxico del español de América: su elemento patrimonial e indígena. Madrid: Mapfre. 
Cáceres-Lorenzo, María-Teresa (2019). "Antillanismos y nahuatlismos dialectales en el español mexicano y centroamericano: análisis comparativo". Studia Neophilologica, 91:1, 97-111.

— (2014). "Differentiation between Indigineous Loanwords in the Spanish American Lexicon”. Bulletin of Hispanic Studies, 91:2, 117-126.

De Luxán Hernández, Lía (2012). “Cómo enfrentarse a la traducción histórica: Estudio de la documentación que se genera entre España y Gran Bretaña con motivo del 'Asiento de Negros"'. López-Folgado, Vicente y Rivas-Carmona, María del Mar (eds.) Essays on Translation. Multiligual Issues, 213-230.

De Zuleta, Emilia (1992). "El hispanismo de Hispanoamérica". The Quincentennial of the Columbian Era. Vol. 75. № 4, 950-965.

Friedrich-Stegmann, Hiltrud (2014). La imagen de España en los libros de los viajeros alemanes del siglo XVIII. Publicaciones de la Universidad de Alicante.

Heine, Wilhelm (1853). Wanderbilder aus Central Amerika. Skizzen eines deutschen Malers Leipzig.

Henríquez Ureña, Pedro (1921) "Observaciones sobre el español en América". Revista de Filología Española 8, 357-390.

Hernández Soca, Elia (2010). Las Islas Canarias en viajeras de lengua alemana. Peter Lang $\mathrm{GmbH}$.

Maar, Wilhelm (1863). Reise nach Central Amerika. San José: Universidad de Costa Rica.

Martinell Gifré, Emma (1992). "La conciencia lingüística en el Viaje de Turquía". En Ariza Vigueira, Manuel (coord.), Actas del II Congreso Internacional de Historia de la Lengua española. Vol. 2.,731-738.

Nida, Eugene (1979). "A Framework for the Analysis and Evaluation of Theories of Translation". Brislin, Richard W. (ed.) Translation: Applications and Research, Nueva York: Gardner Press, 47-91.

Pym, Anthony (1993). "Negotiation theory as an approach to translation history: an inductive lesson from fifteenth-century Castille". Gambier, Y. y Tommola, J. (eds.). Translation and knowledge. SSOTT IV (Scandinavian Symposium on Translation Theory), 73-84.

Raposo Fernández, Berta y García Wistädt, Ingrid (eds.) (2009). Viajes y viajeros entre ficción y realidad. Alemania-España. Universidad de Valencia.

Raposo Fernández, Berta (2014). "Estereotipos entre dos mundos. Viajeros alemanes del siglo XIX en España y Marruecos". Revista de Filología Alemana, Vol. 22, 93-106.

Ribas, Rosa (2005). Testimonios de la conciencia lingüística en textos de viajeros alemanes a América en el siglo XVI. Kasel, Edition Reichenberger.

Santana Quintana, María Cristina (2017). "Contacto de lenguas a través de la asimilación del vocabulario indígena en los textos cronísticos alemanes del siglo XVI: Philipp 
von Hutten y Ulrich Schmidel". Confluencia: Revista Hispánica de Cultura y Literatura. Vol. 33. №1, 2-14.

Sarmiento Pérez, Marcos (2005). Las islas Canarias en los textos alemanes (14941865). Anuart.

Vaquero de Ramírez, María Tránsito (1991). "Español de América y lenguas indígenas". Estudios de lingüística, 7 (1991): 9-26

Venuti, Lawrence (1995). The Translator's Invisibility: A History of Translation. Londres; Nueva York: Routledge.

Wagner, Moritz, Scherzer Karl (1856). Die Republik Costa Rica in Central Amerika mit besonderer Berücksichtigung der Naturverhältnisse und der Frage der deutschen Auswanderung und Colonisation. Reisestudien und Skizzen aus den Jahren 1853 und 1854. Leipzig: Arnoldsche Buchandlung.

Zamora Munné, Juan Clemente (1976). Indigenismos en la lengua de los conquistadores. Río Piedras: Editorial Universitaria de Puerto Rico.

Zamora Vicente, Alonso (1970). Dialectología espanola. Reimpresión. Madrid: Gredos Zimmermann, Klaus (1995). “Aspectos teóricos y metodológicos de la investigación sobre el contacto de lenguas en Hispanoamérica". Zimmermann, Klaus (ed.), Lenguas en contacto en Hispanoamérica. Madrid: Biblioteca Iberoamericana, 9-34. 